\title{
Tsafon
}

Revue d'études juives du Nord

73 | 2017

Connaissance de la Shoah : témoignages, enseignements, visites

\section{Joseph Mélèze-Modrzejewski}

Historien de l'hellénisme

\section{Christophe Batsch}

\section{OpenEdition}

Journals

Édition électronique

URL : https://journals.openedition.org/tsafon/312

DOI : $10.4000 /$ tsafon.312

ISSN : 2609-6420

\section{Éditeur}

Association Jean-Marie Delmaire

Édition imprimée

Date de publication : 1 juin 2017

Pagination : 175-177

ISSN : 1149-6630

\section{Référence électronique}

Christophe Batsch, « Joseph Mélèze-Modrzejewski », Tsafon [En ligne], 73 | 2017, mis en ligne le 31 mai 2018, consulté le 27 juin 2021. URL : http://journals.openedition.org/tsafon/312 ; DOl : https:// doi.org/10.4000/tsafon.312 


\title{
Hommage
}

\section{Joseph Mélèze-Modrzejewski}

\author{
Historien de l'hellénisme
}

Christophe Batsch*

Joseph Mélèze-Modrzejewski, qui avait lui-même ajouté la traduction française à son nom et que ses amis appelaient Jo, est mort à Paris à la fin du mois de janvier 2017. Il allait avoir 87 ans.

Né à Lublin, en Pologne au printemps 1930, Jo Mélèze aura illustré magnifiquement l'apport considérable de ces savants d'Europe orientale que les circonstances historiques et politiques de l'après-guerre ont fait poursuivre leur carrière et leurs recherches dans les universités françaises, anglaises... et autres, pour le plus grand bénéfice de celles-ci.

Déjà docteur en histoire à Varsovie, il entreprit en effet un deuxième cursus en France, à partir de l'année 1958, qui le conduisit à soutenir deux thèses à Paris, l'une en droit, l'autre en sciences humaines. Il fut ainsi amené à enseigner successivement l'histoire du droit, puis l'histoire ancienne, d'abord à la Faculté de droit de Paris puis à la Sorbonne (Université Paris 1). Cette double compétence l'a également bientôt conduit à la tête de la vénérable Revue historique de droit français et étranger à laquelle il sut donner un nouvel élan rédactionnel et scientifique.

Mélèze se révéla en outre un papyrologue exceptionnel, sans doute l'un des meilleurs de sa génération dans cette science historique, toute de technique et d'érudition. C'est à ce titre qu'il fut élu directeur d'étude de papyrologie et d'histoire des droits de l'Antiquité à l'EPHE-IV' section

\footnotetext{
*Université Lille 3, Sciences humaines et sociales.
} 
(sciences historiques et philologiques), où il dirigea un séminaire demeuré légendaire, de 1972 à 2004. Il y étudia en particulier l'histoire juridique et sociale de l'Égypte grecque et romaine à la lumière des sources papyrologiques, ainsi que l'histoire du judaïsme à l'époque du deuxième Temple.

On ne fera pas ici la liste de toute la production scientifique de Mélèze, mais c'est sans doute cette exploitation systématique des sources papyrologiques qui le conduisit à rédiger l'ouvrage que beaucoup jugent l'une des plus importantes contributions à la connaissance du monde juif de l'Antiquité : Les Juifs d'Égypte, de Ramsès II à Hadrien'. Il y passe en revue l'histoire et les conditions d'existence de la très importante communauté juive antique d'Alexandrie dont sont issus bon nombre de traditions, de récits et de créations intellectuelles indissolublement attachés à l'histoire des échanges et des polémiques entre juifs et chrétiens : qu'il suffise de mentionner ici la Septante ou le philosophe Philon.

Sa connaissance aiguisée de la diaspora égyptienne l'amena à traduire du grec un grand pseudépigraphe, d'origine juive alexandrine, de l'Ancien Testament (texte au demeurant reçu dans le canon biblique orthodoxe), connu sous le nom de Troisième livre des Maccabées. Récit romanesque et tragique, un peu sur le modèle d'Esther, d'une tentative d'extermination de la communauté juive d'Alexandrie, tentative qui se retourna contre ses instigateurs ${ }^{2}$.

Par la suite il rédigea encore un ouvrage d'historiographie, dans la lignée des travaux d'Arnaldo Momiglianio où il réfléchissait, à partir de son expérience d'historien et de sa connaissance des textes, sur le destin $\mathrm{du}$ peuple juif et les représentations qui en furent successivement données durant l'Antiquité ${ }^{3}$. On peut voir encore aujourd'hui sur le site d'Akadem l'entretien qu'il accorda à Nicolas Weill à l'occasion de la sortie de ce livre ${ }^{4}$.

\footnotetext{
${ }^{1}$ Les Juifs d'Égypte, de Ramsès II à Hadrien, Paris, Éditions Errance, 1991 et Armand Colin, 1992 ; $2^{\mathrm{e}}$ éd., revue et complétée, Paris, PUF, 1997 (Quadrige 247). En anglais : The Jews of Egypt from Rameses II to Emperor Hadrian, Philadelphie, Jérusalem, The Jewish Publication Society, Édimbourg, T\&T Clark, $1995 ; 2^{\mathrm{e}}$ éd., Princeton, University Press, 1997.

${ }^{2}$ Troisième Livre des Maccabées, traduction du texte grec des Septante ; Introduction et notes de Joseph Mélèze-Modrzejewski. (La Bible d’Alexandrie 15.3), Paris, Éditions du Cerf, 2008.

${ }^{3}$ Un peuple de philosophes. Aux origines de la condition juive, Paris, Fayard, 2011.

4 http://www.akadem.org/magazine/un-peuple-de-philosophes-avec-joseph-meleze-1309-2011-27165_591.php
} 
Au-delà de son érudition, Joseph Mélèze fut un enseignant et un transmetteur chaleureux et généreux. Ceux qui l'ont connu, collègues ou étudiants, garderont le souvenir d'un géant élégant et souriant, optimiste en dépit de tout, amoureux de l'amour, de l'amitié et de la vie.

Tsafon présente ici ses vives condoléances à tous ses enfants et descendants. 